\title{
Endovascular treatment of acute and chronic aortic dissection: Midterm results from the Talent Thoracic Retrospective Registry
}

\author{
Stephan Kische, MD, ${ }^{a}$ Marek P. Ehrlich, MD, ${ }^{\mathrm{b}}$ Christoph A. Nienaber, MD, ${ }^{a}$ Hervé Rousseau, MD, \\ Robin Heijmen, MD, ${ }^{\mathrm{d}}$ Philippe Piquet, MD, Hüseyin Ince, MD, Jean-Paul Beregi, MD, ${ }^{\mathrm{f}}$ and \\ Rossella Fattori, $\mathrm{MD}^{\mathrm{g}}$
}

Objective: This study examined midterm results after treatment with the endovascular Talent thoracic stent graft (Medtronic/AVE, Santa Rosa, Calif) in patients with acute or chronic aortic dissection.

\begin{abstract}
Methods: In the Talent Thoracic Retrospective Registry, 180 patients were treated for acute or chronic aortic dissection (mean age: $59.6 \pm 13.0$ years). Thirty-seven $(20.6 \%$ ) patients had acute aortic complications with signs of rupture, distal malperfusion, or persistent pain; the remainder were in stable condition. Aortic diameter was 53.5 $\pm 14.3 \mathrm{~mm}$, the distance from the left subclavian artery to the proximal entry tear was $44.1 \pm 41.9 \mathrm{~mm}$, and dissection extended beyond the celiac axis in $88.3 \%$ of cases. Length of covered aorta measured $138.9 \pm 45.7 \mathrm{~mm}$, with one stent graft used in $125(69.4 \%)$ patients.
\end{abstract}

Results: Procedural success was $98.3 \%$. Nine patients died within 30 days, yielding an overall early mortality of $5.0 \%$. For in-hospital outcome, multivariate analysis showed that age greater than 75 years (odds ratio [OR] 4,9; $95 \%$ confidence intervals $[\mathrm{CI}] 1.6-15.1 ; P=.006)$, American Society of Anesthesiologists class greater than III (OR 2.8; 95\% CI 1.0-7.5; $P=.04$ ), and emergency status (OR 3.5; 95\% CI 1.3-8.9; $P=.01$ ) were independent predictors of major adverse events. Compared with electively treated patients, emergency status was associated with a higher incidence of in-hospital mortality $(13.5 \%$ vs $2.1 \% ; P=.003)$ and neurologic events $(16.2 \%$ vs $4.2 \% ; P=.01)$. However, patients with acute dissection had a smaller baseline diameter and were less often identified to have secondary endoleaks and progressive enlargement. Average follow-up for hospital survivors was $22.3 \pm 17.0$ months with an estimated survival of $94.9 \% \pm 1.7 \%$ at 30 days, $90.6 \% \pm 2.3 \%$ at 12 months, $90.6 \% \pm 2.3 \%$ at 24 months, and $81.8 \% \pm 4.8 \%$ at 36 months. During follow-up, 30 patients required a total of 32 secondary interventions including 12 open and 20 endovascular procedures, accounting for an estimated $71.5 \%$ freedom from reinterventions at 36 months. Follow-up imaging revealed stable or decreasing thoracic aortic diameter in $80.5 \%$ of patients.

Conclusion: Endovascular treatment for aortic dissection is associated with reasonably low morbidity and mortality. Long-term surveillance is crucial to define more comprehensively the durability of stent graft treatment of aortic dissection and to determine which patients are appropriate candidates for stent graft therapy.

Aortic dissection remains a catastrophic cardiovascular event associated with high morbidity and mortality rates. ${ }^{1}$ Improved diagnostic techniques and refined management strategies have shown potential to improve diagnosis and

\footnotetext{
From the Department of Cardiology, Division of Cardiology, ${ }^{a}$ University Hospital Rostock, Germany; the Department of Cardiothoracic Surgery, ${ }^{b}$ University of Vienna, Austria; the Department of Radiology, ${ }^{\mathrm{c}}$ Centre Hospitalier Universitaire, Hopital de Rangueil, Toulouse, France; the Department of Cardiothoracic Surgery, ${ }^{\mathrm{d}}$ St Antonius Hospital, Nieuwegein, The Netherlands; Centre Hospitalier Universitaire, ${ }^{\mathrm{e}}$ Hopital Sainte Marguerite, Marseille, France; Radiologie Vasculaire, ${ }^{\mathrm{f}}$ Hopital Cardiologique CHRU de Lille, Lille, France; and Cardiovascular Radiology, ${ }^{\mathrm{g}}$ University Hospital S. Orsola, Bologna, Italy.

Read at the Eighty-eighth Annual Meeting of The American Association for Thoracic Surgery, San Diego, Calif, May 10-14, 2008.

Received for publication May 9, 2008; revisions received July 11, 2008; accepted for publication July 26, 2008 .

Address for reprints: Christoph A. Nienaber, MD, Department of Cardiology, University of Rostock, D-18057 Rostock, Germany (E-mail: christoph.nienaber@med. uni-rostock.de)

J Thorac Cardiovasc Surg 2009;138:115-24

0022-5223/\$36.00

Copyright $(c) 2009$ by The American Association for Thoracic Surgery

doi:10.1016/j.jtcvs.2008.07.074
}

management. Recent insights from international registries have contributed to understand epidemiology and pathophysiology of aortic dissection. ${ }^{2-4}$ Different from proximal dissection, however, management of patients with distal dissection (Stanford type B) remains a matter of ongoing debate. ${ }^{5,6}$ Contemporary mortality rates of surgical resection of the descending aorta range between $0 \%$ and $27 \%$ for elective cases and exceed $50 \%$ in complicated aortic dissection under emergency conditions. ${ }^{1,7}$ Similar to demographic changes in the Western world, the population at risk is aging with an increasing variety of comorbidities portending an incremental risk. Today, most institutions favor a complication-specific approach with medical treatment as the primary therapeutic option, while reserving surgery for evolving complications (eg, persistent pain, false lumen expansion, visceral or peripheral malperfusion, or [imminent] rupture). ${ }^{5}$ Even without complications, however, both short-term and long-term prognoses of type B aortic dissection remain sobering despite optimal medical therapy. 


\author{
Abbreviations and Acronyms \\ ASA $=$ American Society of Anesthesiologists \\ $\mathrm{CI}=$ confidence interval \\ $\mathrm{CT}=$ computed tomography \\ MRI = magnetic resonance imaging \\ $\mathrm{OR}=$ odds ratio \\ TTR $=$ Talent Thoracic Retrospective Registry
}

Survivals at 3 years decrease to $75 \%{ }^{8,9}$; uncontrolled hypertension, advanced age, and persistent perfusion of the false lumen have been identified as predictors of adverse outcome. ${ }^{10,11}$ In this scenario, endovascular stent grafting has emerged as an attractive therapeutic concept even in patients unfit for open surgery. ${ }^{12,13}$ Several single-center reports have shown feasibility and clinical safety, thus emphasizing endovascular repair for aortic dissection. ${ }^{14-16}$ In the absence of final data from randomized trials, ${ }^{17}$ smoldering critique is ongoing with concerns of device failure and long-term durability of stent grafts.

The Talent Thoracic Retrospective Registry (TTR) was designed to collect outcome data from patients who underwent endoluminal treatment with the Talent thoracic stent graft (Medtronic/AVE, Santa Rosa, Calif) in 7 European referral centers. ${ }^{2}$ Clinical and imaging follow-up data were collected with particular reference to mortality and midterm complications. The present subanalysis of the TTR registry comprises data on patients subjected to endovascular stent graft placement for acute or chronic aortic dissection.

\section{PATIENTS AND METHODS \\ Enrolment}

The current analysis from the TTR registry is focused on 180 consecutive patients who underwent endovascular repair with the Talent thoracic stent graft for aortic dissection between November 1996 and March 2004. This subgroup represents $39.4 \%$ from a total of 457 patients with thoracic aortic disease collected for the TTR registry. Seven European referral centers (Bologna, Lille, Marseille, Nieuwegein, Rostock, Toulouse, and Vienna) provided data from patients treated consecutively for thoracic aortic disease. The TTR registry was approved by the local ethical committee. Followup analysis was formed on clinical and imaging findings until the last visit and includes all adverse events. Data were collected on case report forms and checked for inconsistencies. In case of discrepancies, the attending investigator was queried to ensure appropriate interpretation of events.

\section{Patient Characteristics}

The dissection subgroup of TTR comprises 134 male and 46 female patients with an age of $59.6 \pm 13.0$ years, ranging from 22 to 82 years (Table 1). American Society of Anesthesiologists (ASA) classification greater than class III was present in $31(17.2 \%)$. Previous aortic surgery or endovascular aortic repair was reported in $46(25.6 \%)$ patients. The spectrum of aortic disease implied $171(95.0 \%)$ patients with Stanford type B and $9(5.0 \%)$ patients with thoracoabdominal type A dissection. All patients with type A dissection had been previously operated for acute proximal dissection and were electively treated with descending thoracic stent grafts in the chronic stage of disease. Comorbid medical conditions comprised chronic hyperten-
TABLE 1. Demographics and clinical baseline characteristics $(\mathbf{n}=$ 180)

\begin{tabular}{|c|c|c|}
\hline & No. & $\%$ \\
\hline Male & 134 & 74.4 \\
\hline Age, y (mean \pm SD) & $59.6 \pm 13.0(22-82)$ & \\
\hline ASA class (>III) & 31 & 17.2 \\
\hline Patient status (acute) & 37 & 20.6 \\
\hline Aortic and aortic valve procedures & 46 & 25.6 \\
\hline Bentall procedure & 18 & 10.0 \\
\hline Ascendens graft & 16 & 8.9 \\
\hline Elephant trunk & 4 & 2.2 \\
\hline Descendens graft & 3 & 1.7 \\
\hline Surgical fenestration & 2 & 1.1 \\
\hline Single AVR & 2 & 1.1 \\
\hline Infrarenal graft & 1 & 0.6 \\
\hline Bare stent abdominal & 1 & 0.6 \\
\hline \multicolumn{3}{|l|}{ Comorbidity and etiology } \\
\hline Hypertension & 156 & 86.7 \\
\hline Marfan syndrome & 15 & 8.3 \\
\hline Aortic trauma & 5 & 2.8 \\
\hline Renal insufficiency & 34 & 18.9 \\
\hline COPD & 23 & 12.8 \\
\hline CVA & 10 & 5.6 \\
\hline Smoking & 78 & 43.3 \\
\hline \multicolumn{3}{|l|}{ Aortic dissection } \\
\hline Stanford type A & 9 & 5.0 \\
\hline Stanford type B & 171 & 95.0 \\
\hline Abdominal dissection & 158 & 88.3 \\
\hline $\begin{array}{l}\text { Mean aortic diameter, mm } \\
\quad(\text { mean } \pm \mathrm{SD} \text {, range })\end{array}$ & $53.5 \pm 14.3(26-136)$ & \\
\hline $\begin{array}{l}\text { Length LSA to entry, mm } \\
(\text { mean } \pm \mathrm{SD} \text {, range })\end{array}$ & $44.1 \pm 41.9(0-220)$ & \\
\hline
\end{tabular}

$S D$, Standard deviation; $A S A$, American Society of Anesthesiologists; $A V R$, aortic valve replacement; $C O P D$, chronic obstructive pulmonary disease; $C V A$, cerebrovascular accident; $L S A$, left subclavian artery.

sion $(\mathrm{n}=156,86.7 \%)$, renal insufficiency $(\mathrm{n}=34,18.9 \%)$, chronic obstructive pulmonary disease $(n=23,12.8 \%)$, Marfan syndrome $(n=15,8.3 \%)$, and previous cerebrovascular accidents $(n=10,5.6 \%)$. Indications for stent graft deployment included complicated acute type B dissection in 29 patients $(16.1 \%)$, although the majority of patients were treated for chronic dissection with a diameter more than $5.5 \mathrm{~cm}(\mathrm{n}=83,46.1 \%)$, rapid progression greater than $10 \mathrm{~mm} / \mathrm{year}(\mathrm{n}=60,33.3 \%)$, and signs of (impending) rupture $(\mathrm{n}=8,4.4 \%)$. On aggregate, 37 patients $(20.6 \% ; 29$ acute and 8 chronic dissections) were subjected to emergency repair for symptomatic disease with signs of (impending) rupture, distal malperfusion, or persistent pain; all other patients $(79.4 \%)$ were electively treated in stable condition.

\section{Imaging Before Endovascular Treatment}

Before endovascular treatment all patients were examined by at least one tomographic imaging modality, such as computed tomography (CT) and magnetic resonance imaging (MRI), in addition to angiography or transesophageal echocardiography. Contrast-enhanced $\mathrm{CT}$ was the most frequently used diagnostic method $(61.7 \%)$, followed by angiography $(61.1 \%)$, MRI $(47.2 \%)$, and transesophageal echocardiography (27.8\%). In $30 \%$ of cases only one imaging modality was obtained, whereas at least two imaging techniques were used in $70 \%$ of cases. Mean aortic diameter for thoracic dissection was 53.5 $\pm 14.3 \mathrm{~mm}$ (range $26-136 \mathrm{~mm}$ ) and the distance from the origin of subclavian artery to the proximal entry side was $44.1 \pm 41.9 \mathrm{~mm}$ (range $0-220 \mathrm{~mm}$ ); dissection extended beyond the celiac trunk in $88.3 \%$ of cases (Table 1). 


\section{Follow-up}

The follow-up protocol included contrast-enhanced aortic imaging with CT or MRI technique before hospital discharge, 6 and 12 months after stent graft placement, and yearly thereafter. Because the majority of patients were not followed up in each of the 7 centers, compliance with the imaging surveillance protocol was variable. Follow-up clinical status was obtained by contacting all surviving patients or family members and their primary care physician and was $100 \%$ complete. Follow-up averaged $22.3 \pm 17.0$ months (maximum follow-up 71 months; total cumulative follow-up 318 patient-years; 19 patients remained at risk at 4 years).

\section{Definitions}

Procedural success was defined as successful deployment of the stent graft device. Primary success was defined as complete exclusion of the false lumen without any additional intervention. Secondary success was defined as complete exclusion of the aneurysm after secondary intervention. Endoleak was defined as radiologic evidence of blood flow outside the stent graft and was classified as primary (diagnosed within 30 days of endovascular repair) or secondary (diagnosed more than 30 days after intervention).

\section{Statistical Analysis}

The incidence of adverse events is given as number of patients experiencing the event followed by the corresponding percentage. Continuous data are reported as mean \pm standard deviation including range. For intergroup comparison of incidence rates, the 2 -sided $\chi^{2}$ test was used for categorical variables. The Kaplan-Meier nonparametric method was used to generate estimates of survival. Stepwise logistic regression analysis was performed to determine predictors of predefined clinical end points. Noncorrelated variables with $P<.05$ at univariate analyses were included in the multivariate models; model precision was evaluated by the HosmerLemeshow goodness-of-fit statistic. Results are reported as odds ratios and $95 \%$ confidence intervals $(95 \% \mathrm{CI})$. Statistical analyses were carried out with SPSS software package version 15.0 (SPSS, Inc, Chicago, Ill).

\section{RESULTS}

\section{Procedural Results}

Procedural success was documented in $98.3 \%$ of cases; an endovascular graft could not be deployed in 2 patients with previous elephant trunk for type A dissection, and stent graft insertion was impossible in another patient with severely calcified access vessels. Those procedures were terminated at the discretion of the operator for fear of procedure-related complications. The mean length of covered aorta was 139 $\mathrm{mm}$, ranging from 28 to $380 \mathrm{~mm}$ with only one stent graft used in $125(69.4 \%)$ patients. In $27(15.3 \%)$ patients the stent graft was positioned in the distal arch with coverage of the left subclavian artery to extend the proximal landing zone; in $18.5 \%$ of them (5 patients) ancillary carotid-subclavian bypass surgery was performed before stent graft placement. Adjunctive maneuvers such as side-branch coiling to prevent type II endoleak or abdominal fenestration for peripheral malperfusion were performed in 5 patients (Table 2 ). Early procedural outcome (30 days). Nine patients died during hospitalization, yielding an overall in-hospital mortality rate of $5.0 \%(9 / 180)$. Two of them died during the endovascular procedure; both had required emergency treatment for ruptured type B dissection. In-hospital mortality of patients undergoing stent graft treatment for acute
TABLE 2. Procedural detail and 30-day outcome

\begin{tabular}{|c|c|c|}
\hline & No. & $\%$ \\
\hline Procedural success & 177 & 98.3 \\
\hline Length of covered aorta, mm (mean \pm SD) & $\begin{array}{c}138.9 \pm 45.7 \\
(28-380)\end{array}$ & \\
\hline \multicolumn{3}{|l|}{ No. of stent grafts used } \\
\hline Zero & 3 & 1.7 \\
\hline One & 125 & 69.4 \\
\hline Two & 40 & 22.2 \\
\hline Three & 11 & 6.1 \\
\hline Four & 1 & 0.6 \\
\hline Occlusion of LSA & 27 & 15.3 \\
\hline With previous revascularization & 5 & \\
\hline Without previous revascularization & 22 & \\
\hline \multicolumn{3}{|l|}{ Early mortality } \\
\hline Thirty-day mortality & 9 & 5.0 \\
\hline Intraprocedural death & 2 & 1.1 \\
\hline \multicolumn{3}{|l|}{ Adjunctive intraprocedural maneuvers } \\
\hline Side branch coiling (LSA, lusorian) & 3 & 1.7 \\
\hline Fenestration of abdominal aorta & 2 & 1.1 \\
\hline \multicolumn{3}{|l|}{ Procedural failure and redo, intervention } \\
\hline Impossibility to insert or deploy stent graft & 3 & 1.7 \\
\hline Conversion to aortic surgery & 5 & 2.8 \\
\hline Additional stent graft & 2 & 1.1 \\
\hline Primary endoleak & 52 & 29.4 \\
\hline \multicolumn{3}{|l|}{ Vascular local procedures } \\
\hline Revision of retroperitoneal hematoma & 1 & 0.6 \\
\hline Subclavian to carotid transposition & 1 & 0.6 \\
\hline Iliofemoral bypass & 1 & 0.6 \\
\hline Iliorenal bypass & 1 & 0.6 \\
\hline \multicolumn{3}{|l|}{ Early complications } \\
\hline Neurologic & 12 & 6.7 \\
\hline Stroke & 7 & 3.9 \\
\hline Spinal cord ischemia & 5 & 2.8 \\
\hline Cardiorespiratory failure & 6 & 3.3 \\
\hline Vascular local & 4 & 2.2 \\
\hline Retrograde dissection & 4 & 2.2 \\
\hline ARDS & 2 & 1.1 \\
\hline Pulmonary embolism & 1 & 0.6 \\
\hline Multiorgan failure & 1 & 0.6 \\
\hline Length of hospital stay (d) & $12.7 \pm 10.6$ & \\
\hline
\end{tabular}

LSA, Left subclavian artery; $A R D S$, adult respiratory distress syndrome.

complications was higher than that for those receiving elective therapy $(13.5 \%$ vs $2.1 \% ; P=.003)$. Multivariate logistic regression analysis showed that ASA class greater than III (odds ratio [OR] 10.9; 95\% CI 2.4-49.6; $P=.002$ ) and age greater than 75 years (OR 8.7; CI 1.8-42.5; $P=$ $.007)$ were independent predictors of 30-day mortality. For in-hospital outcomes, multivariate logistic regression analysis revealed age greater than 75 years (OR $4.9 ; 95 \%$ CI 1.6 $15.1 ; P=.006)$, ASA class greater than III (OR $2.8 ; 95 \% \mathrm{CI}$ $1.0-7.5 ; P=.04)$, and emergency status (OR $3.5 ; 95 \% \mathrm{CI}$ $1.3-8.9 ; P=.01)$ as independent predictors of in-hospital adverse events (Table 3). Early emergency conversion was required in 3 patients with retrograde type A dissection and in 2 patients with rapidly enlarging false lumen and 
TABLE 3. Predictors of 30-day-mortality and in-hospital adverse events

\begin{tabular}{|c|c|c|c|c|}
\hline \multirow[b]{2}{*}{ Analysis } & \multirow{2}{*}{$\begin{array}{c}\text { Univariate } \\
P \text { value }\end{array}$} & \multicolumn{3}{|c|}{ Multivariate } \\
\hline & & OR & $95 \% \mathrm{CI}$ & $P$ value \\
\hline \multicolumn{5}{|l|}{ Thirty-day mortality } \\
\hline ASA class (>III) & $<.001$ & 10.9 & $2.4-49.6$ & .002 \\
\hline Age $(>75$ y) & $<.001$ & 8.7 & $1.8-42.5$ & .007 \\
\hline Male & .39 & & & \\
\hline Emergency status & .003 & & & \\
\hline Traumatic aortic injury & .63 & & & \\
\hline Diameter $(>65 \mathrm{~mm})$ & .49 & & & \\
\hline Marfan syndrome & .39 & & & \\
\hline Type of dissection & .51 & & & \\
\hline Relevant aortic surgery & .09 & & & \\
\hline Occluded LSA & .22 & & & \\
\hline \multicolumn{5}{|l|}{ In-hospital complications } \\
\hline ASA class (>III) & $<.001$ & 2.8 & $1.0-7.5$ & .04 \\
\hline Age $(>75$ y) & $<.001$ & 4.9 & $1.6-15.1$ & .006 \\
\hline Male & .02 & & & \\
\hline Emergency status & $<.001$ & 3.5 & $1.3-8.9$ & .01 \\
\hline Traumatic aortic injury & .84 & & & \\
\hline Diameter $(>65 \mathrm{~mm})$ & .24 & & & \\
\hline Marfan syndrome & .72 & & & \\
\hline Type of dissection & .65 & & & \\
\hline Relevant aortic surgery & .20 & & & \\
\hline Occluded LSA & .82 & & & \\
\hline
\end{tabular}

$O R$, Odds ratio; $C I$, confidence intervals; $A S A$, American Society of Anesthesiologists; $L S A$, left subclavian artery.

persisting aortic hemorrhage, respectively, accounting for a 30-day conversion rate of $2.8 \%$. Finally, in 2 patients with impending rupture, satisfactory exclusion of the false lumen was achieved by additional sealing with an overlapping second stent graft. Periprocedural stroke was documented in $7(3.9 \%)$ patients. Spinal cord ischemia was observed in $5(2.8 \%)$ but was not significantly associated with the use of multiple stent grafts, coverage of the left subclavian artery, or emergency condition. At follow-up, spinal cord damage resolved completely in 2 of 5 patients.

Mortality and aortic rupture at midterm. Mean followup period for hospital survivors was $22.3 \pm 17.0$ months (1.0-71.0 months) (Table 4); in $64.9 \%$ of patients more than 12 months of clinical and imaging follow-up was available. Late death occurred in 11 of $168(6.5 \%)$ patients and was related to rupture in $7(63.6 \%)$. In these patients aortic death was related to spontaneous rupture of the ascending aorta $(\mathrm{n}=1)$, retrograde type A dissection $(\mathrm{n}=1)$, and rupture of a descending false lumen $(n=5)$. Other causes of deaths included stroke, bronchial carcinoma, and myocardial infarction. Kaplan-Meier overall survival was 94.9\% $\pm 1.7 \%$ at 30 days, $90.6 \% \pm 2.3 \%$ at 12 months, $90.6 \%$ $\pm 2.3 \%$ at 24 months, and $81.8 \% \pm 4.8 \%$ at 36 months. Estimates for freedom from aortic rupture were $99.4 \% \pm 0.6 \%$ at 30 days, $95.0 \% \pm 1.9 \%$ at 12 months, $95.0 \% \pm 1.9 \%$ at 24 months, and $89.6 \% \pm 4.1 \%$ at 36 months (Figure 1). In multivariate logistic regression analysis, poor clinical health
TABLE 4. Follow-up data $(22.3 \pm 17.0$ months $)$ in 168 patients

\begin{tabular}{lrr}
\hline & No. & $\%$ \\
\hline Mortality & 11 & \\
Overall & 7 & 6.5 \\
$\quad$ Related & & 4.2 \\
Procedural failure & 33 & \\
Persistent primary endoleak & 8 & 19.6 \\
Persistent secondary endoleak & 7 & 4.8 \\
Fatal aortic rupture & 3 & 4.2 \\
Retrograde extension & 12 & 1.8 \\
Conversion to surgery & 15 & 7.1 \\
Second stent graft & & 8.9 \\
Stent graft complications & 1 & \\
Migration & 1 & 0.6 \\
Modular disconnection & 0 & 0.6 \\
Altered graft integrity & 0 & 0.0 \\
Stent fracture & & 0.0 \\
Change in diameter $(\mathrm{n}=164)$ & 32 & \\
Increase & 41 & 25.0 \\
Decrease & 91 & 55.5 \\
No change &
\end{tabular}

status (ASA class $>$ III; OR 3.8, 95\% CI 1.4-10.6; $P=.01$ ) and older age ( $>70$ years, OR $3.0,95 \%$ CI $1.1-8.1 ; P=$ .028 ) were the only significant predictors of late death.

Secondary procedures. During follow-up, 30 patients required a total of 32 additional interventions including 12 late surgical conversions and 20 adjunctive endovascular procedures. Thus, the total reintervention rate was $17.9 \%$ (30/168) for survivors of index hospitalization. Indication for open surgery included presence of endoleaks $(n=6)$, enlargement of the distal false lumen $(n=2)$, retrograde type A dissection $(\mathrm{n}=2)$, hybrid aortic arch procedure $(\mathrm{n}=1)$, and recurrent dissection of the ascending aorta $(n=1)$ after failed glue reconstruction. All patients survived the surgical procedure without related fatalities. Univariate predictors for late conversion to surgery were Marfan syndrome $(P<$ $.001)$, secondary endoleak $(P=.015)$, diameter greater than $60 \mathrm{~mm}(P=.032)$, and age of 65 years or older $(P=$ .04). In multivariate logistic regression analysis, Marfan syndrome was the only independent predictor of late conversion (OR 32.3; 95\% CI 6.0-175.2; $P<.001$ ). Additionally, 20 catheter-based interventions were performed during follow-up, again with no in-hospital mortality. Fifteen patients required a second stent graft for persisting false lumen flow $(n=13)$ or aortic ulcer $(n=2)$. One patient with developing aneurysm of the aortic arch underwent a hybrid procedure with proximal stent graft extension after head vessel debranching; in another 3 patients endoleaks were sealed with coil embolization. Stenting of both renal arteries was performed to restore organ perfusion in 1 patient with acute renal failure owing to shifting of dissection lamella. The presence of primary $(P=.027)$ or secondary endoleak $(P<.001)$, diameter greater than $60 \mathrm{~mm}(P=.015)$, and previous aortic surgery $(P=.042)$ were univariate predictors of 

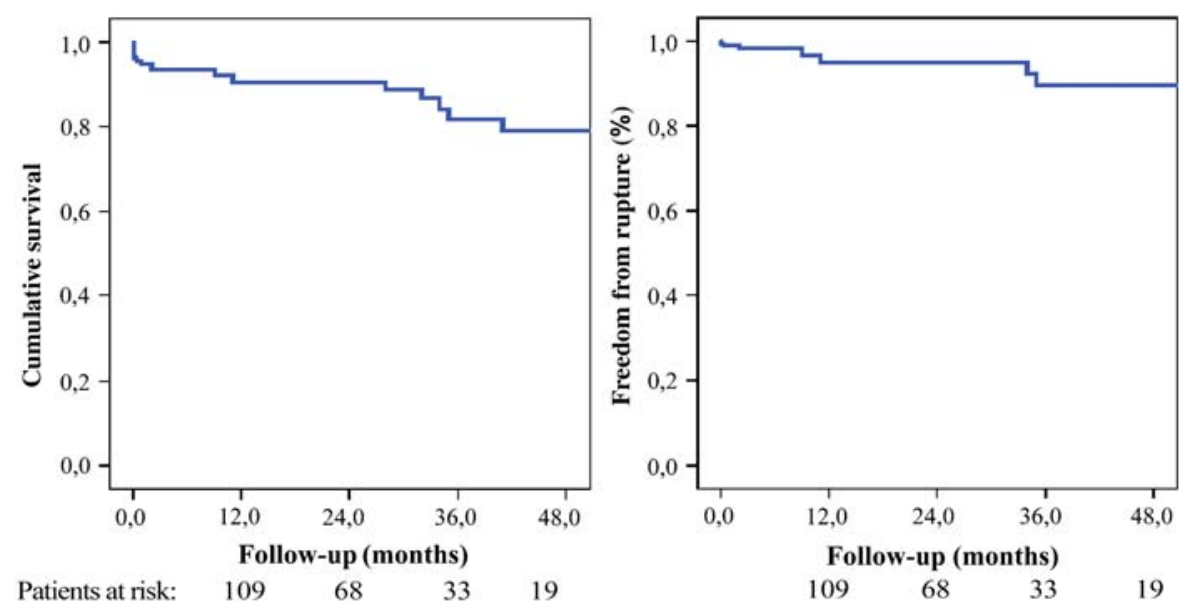

FIGURE 1. Overall survival and freedom from rupture after stent graft repair in thoracic aortic dissection.

late endovascular maneuvers. Freedom from both open and endoluminal reintervention was $94.7 \% \pm 1.7 \%$ at 30 days, $83.5 \% \pm 3.1 \%$ at 12 months, $75.5 \% \pm 4.0 \%$ at 24 months, and $71.5 \% \pm 4.7 \%$ at 36 months (Figure 2).

Imaging follow-up. Primary endoleak was documented in 52 of $177(29.4 \%)$ patients. However, 7 endoleaks sealed spontaneously during follow-up, whereas an adjunctive endovascular treatment with stent graft extension (7 patients) or embolization ( 3 patients) allowed complete resolution of endoleak in 7 patients. Five cases of primary endoleak and aneurysm expansion were converted to open surgical repair. Therefore, the rate of persistent primary endoleak for in-hospital survivors was $19.6 \%$ (33/168 patients). Endoleak type I was most common $(86.5 \%)$, whereas the incidence of both type II $(11.5 \%)$ and type III (1.9\%) was low. Secondary endoleak (types I and III) was reported in 17 of $168(10.1 \%)$ patients who had survived the early postoperative course. Adjunctive stent graft treatment allowed successful endoleak sealing in 5 of 6 patients; an additional 4 patients underwent conversion to open repair for progressive false lumen enlargement. Seven patients did not undergo treatment for secondary endoleak; among them, no case of spontaneous resolution was recorded. As a result, persistent secondary perigraft flow was documented in $8(4.8 \%)$ patients.

The dynamics of aneurysm dimension were reported in 164 patients. Among them, stable $(\mathrm{n}=91)$ or decreasing $(\mathrm{n}=41)$ aortic diameter was reported in a total of $132(80.5 \%)$ patients, whereas $32(19.5 \%)$ patients showed an increase of the aneurysmal process. Migration of a single stent graft was observed in 1 patient, who was converted to open surgery for a secondary type I endoleak. In addition, follow-up imaging visualized late modular disconnection in another patient, who had a lethal aortic rupture. Alteration of the graft material or detachment of nitinol frames was not identified.

Interventions in an elective versus an emergency setting. Patients with thoracic aortic emergencies had a worse general health status than patients having elective operations
(ASA $>$ III, 48.6 vs $9.1 \% ; P<.001$ ). The overall survival after emergency stent grafting in 37 patients was $86.2 \% \pm$ $5.7 \%$ at 30 days, $83.2 \% \pm 6.3 \%$ at 12 months, and $83.2 \% \pm 6.3 \%$ at 3 years, respectively. Survival for patients in an elective setting was $97.1 \% \pm 1.4 \%$ at 30 days, $92.6 \%$ $\pm 2.4 \%$ at 12 months, and $81.9 \% \pm 5.5 \%$ at 3 years, respectively (Figure 3). In-hospital complications, including fatal and nonfatal major adverse events, were documented more frequently in symptomatic patients requiring instantaneous endovascular treatment $(40.5 \%$ vs $10.5 \% ; P<.001)$. Particularly, neurologic events were reported more often in this subgroup $(16.2 \%$ vs $4.2 \%$ in elective cases; $P=.01)$. Patients with emergency status had a smaller baseline diameter and were less often identified to have secondary endoleaks. Accordingly, those patients revealed a significantly lower rate of progressive aortic enlargement when compared with electively treated patients $(3.2 \%$ vs $23.3 \% ; P=.001)$.

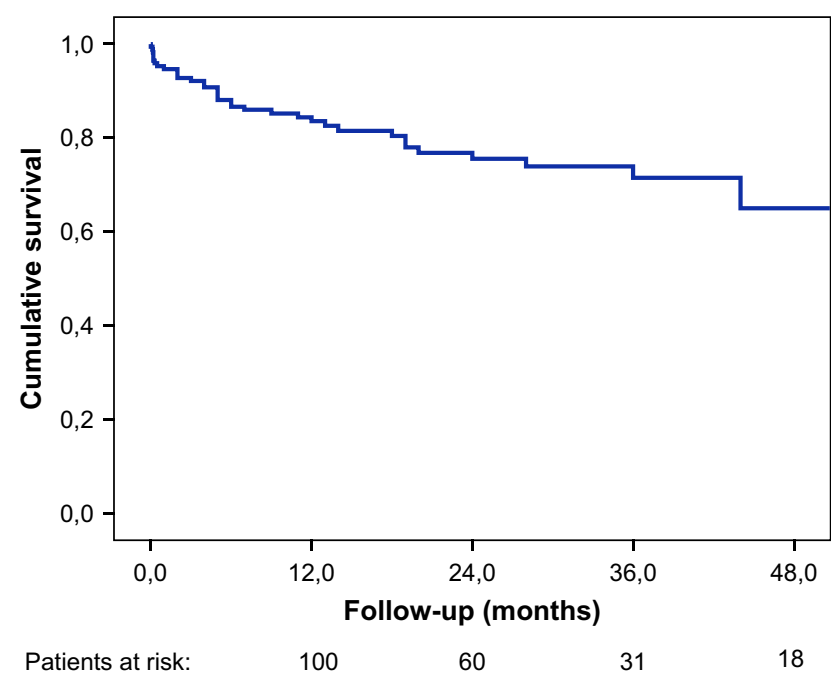

FIGURE 2. Freedom from secondary open and endoluminal aortic procedures. 


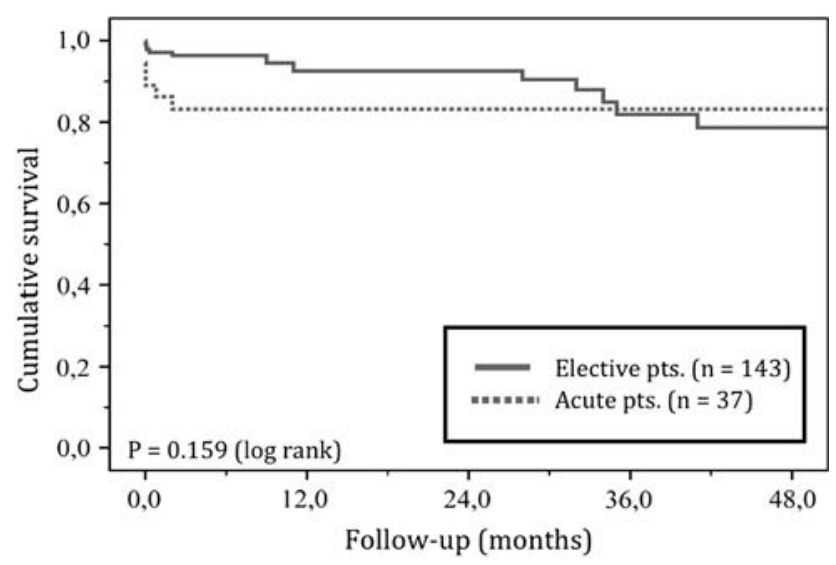

FIGURE 3. Survival after stent graft treatment in thoracic emergencies versus an elective setting.

Albeit statistically not significant, there was a lower rate of secondary procedures and fatal aortic rupture after stent graft repair for acute aortic dissection.

Stent grafts after surgical treatment of type A dissection. Nine patients were electively treated for persistent distal false lumen flow after previous surgery for type A dissection. Among them, Marfan syndrome $(44.4 \%$ vs $6.4 \%$; $P<.001)$ and baseline diameter greater than $60 \mathrm{~mm}$ $(55.6 \%$ vs $21.6 \% ; P=.019)$ were reported more frequently when compared with those of patients with type B dissection. Previous diagnosis of type A dissection did not increase in-hospital complications and early mortality rate after stent graft treatment. In contrast, primary endoleaks were detected more often in patients with type A dissection $(66.6 \%$ vs $27.4 \%$ in type $\mathrm{B} ; P=.012$ ), resulting in a higher rate of chronic enlargement $(44.4 \%$ vs $17.2 \% ; P=.042)$ and rupture $(22.2 \%$ vs $4.1 \% ; P=.015)$. Consistently, endovascular and open reinterventions for procedural failure were reported more often in patients with previous type A dissection. However, at midterm, overall mortality rate of type A dissection was not significantly higher than for classic type B dissection.

Retrograde extension of type $B$ dissection. Retrograde extension of type B dissection was documented in 7 patients after endovascular treatment; in 3 cases, the patient had been treated under emergency conditions. Retrograde extension occurred within 30 days in 4 of $7(57.1 \%)$ patients. Five patients were operated on and survived the complex procedure without major complications. The remaining 2 patients died before transfer to the operating theater. In multivariate logistic regression analysis, use of more than one stent graft was the only independent predictor for retrograde extension of aortic dissection (OR 7.6; 95\% CI 1.3-43.9; $P=.023$ ).

\section{DISCUSSION}

In 1999, endovascular treatment of type B dissections with stent graft technology was first described in two seminal reports, raising optimism for improved early and late survival. ${ }^{12,13}$ The concept was propelled by the desire to induce aortic remodeling after sealing the proximal entry tear, redirecting flow into the true lumen, and promoting depressurization and thrombosis of the false lumen. In addition, such an approach may effectively treat malperfusion syndrome by re-establishing side branch flow in dynamic obstruction. ${ }^{18,19}$ Growing experience with endovascular treatment in the spectrum of aortic dissection has confirmed both feasibility and usefulness, especially in unstable patients, with encouraging early and midterm results. ${ }^{20}$ However, residual perigraft flow and late reperfusion of the false lumen have been observed occasionally, underlining the need for stringent follow-up imaging and additional stent graft placement in selected patients. ${ }^{21}$

Our analysis focuses on 180 patients with thoracic aortic dissection extracted from the TTR registry and demonstrates that endovascular repair using the Talent stent graft is feasible, with high technical success rates and low incidence of associated complications. Early postinterventional results are consistent with previous observational evidence with an in-hospital mortality of $5.0 \%$, including 37 patients treated for complications under emergency conditions. Our results indicate that early outcome after endovascular repair significantly depends on pre-existing conditions. Patients undergoing urgent stent graft placement for complicated dissection were found to be at higher risk for major in-hospital complications than those treated in an elective setting $(40.5 \%$ vs $10.5 \% ; P<.001)$. Accordingly, emergency interventions were often prompted by complications of the dissection with an inherently increased individual risk as compared with chronic dissection. Our findings are consistent with a recently published meta-analysis showing higher in-hospital mortality in patients undergoing stent graft placement for acute dissection than for chronic dissection. Conversely, patients treated for acute complication of dissection have a greater potential for aortic remodeling (Figure 4), which is consistent with previous observations that false lumen obliteration after stent graft placement was more frequently achieved in patients with acute dissection than in patients treated for chronic disease. ${ }^{3,22,23} \mathrm{On}$ the other hand, we confirm feasibility of successful endovascular procedures with satisfactory clinical outcome in chronic dissection (Figure 5). However, patients with chronic dissection more often seem to require late surgical or endovascular reinterventions and also have more late complications.

In the TTR registry, persistent paraplegia occurred in only $3(1.7 \%)$ patients. Different from previous reports, enduring spinal injury was not associated with use of multiple endografts, previous aortic surgery, or emergency stent grafting. In addition, the registry confirms a $3.9 \%$ incidence of periprocedural stroke, similar to previous observations. ${ }^{3,24,25}$ It is commonly believed that stroke is related to difficult advancement and manipulation of the guide wire or stent graft 

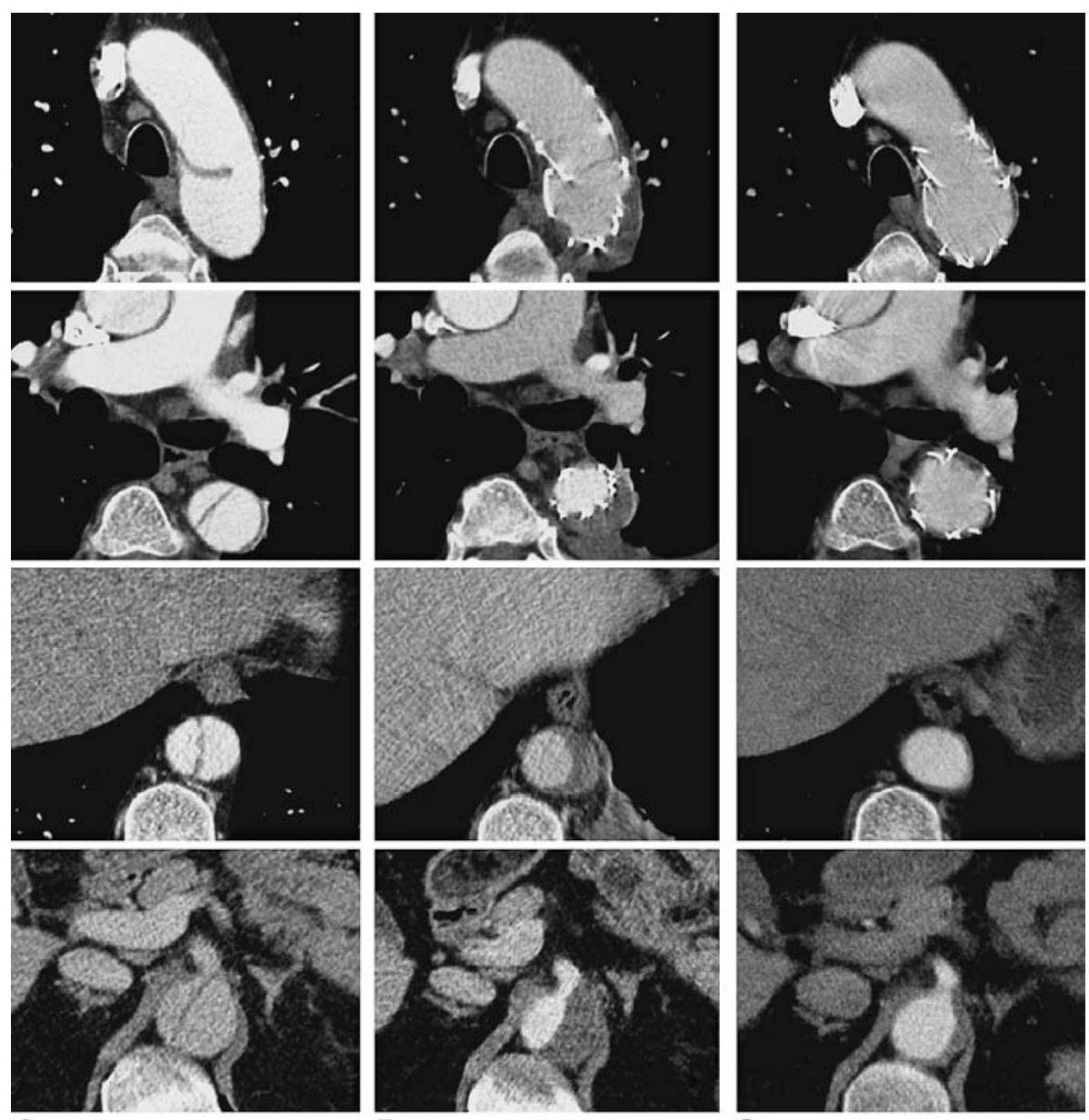

A

B

C

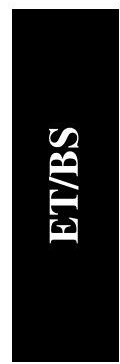

delivery system within the aortic arch. Technical developments and miniaturization of the relatively rigid stent graft devices will thus be even more relevant for treating degenerative aneurysmal diseases than for aortic dissection. Our analysis shows that periprocedural stroke was significantly associated with increased age, emergency stent grafting, and higher ASA class. With regard to intentional left subclavian artery occlusion, accumulated observational evidence suggests this approach may be justified when required for proximal anchoring of the stent graft in the absence of supra-aortic vascular diseases. ${ }^{26}$ In dissection, prophylactic surgical revascularization appears not to be imperative for safety reasons and can be relegated to an elective measure after the intervention when symptoms of ischemia occur. In this registry, subclavian bypass was necessary in only 1 patient with sustained malperfusion of the left arm after left subclavian artery occlusion.

Similar to previous reports, ${ }^{27}$ retrograde extension of the dissection into the ascending aorta, potentially caused by stent graft-induced intimal injury, has been replicated in 7 patients in the registry, which represent $3.9 \%$ of patients with an overall mortality rate of $28.6 \%$. It is, however, unclear whether retrograde dissection after stent graft repair is a true complication or suggestive of progressive disease.

Besides reasonable short-term outcome, long-term survival is the key issue of endovascular reconstruction in aortic dissection. For midterm outcome at 36 months, the KaplanMeier plot indicates an $81.8 \%$ overall survival and an $89.9 \%$ estimated freedom from aortic fatalities after endovascular reconstruction. Long-term results confirm that poor clinical health status and older age were independent predictors of life expectancy after stent graft placement. In chronic dissection and elective settings, stent grafting fails to abolish the false lumen in about a quarter of patients, suggesting that it may not be a definitive treatment option. Yet, there is a continued risk of late aortic rupture (about $4 \%$ during follow-up) after stent graft placement and need for secondary aortic procedures in about $20 \%$ of patients. However, among those, only 12 patients required open 

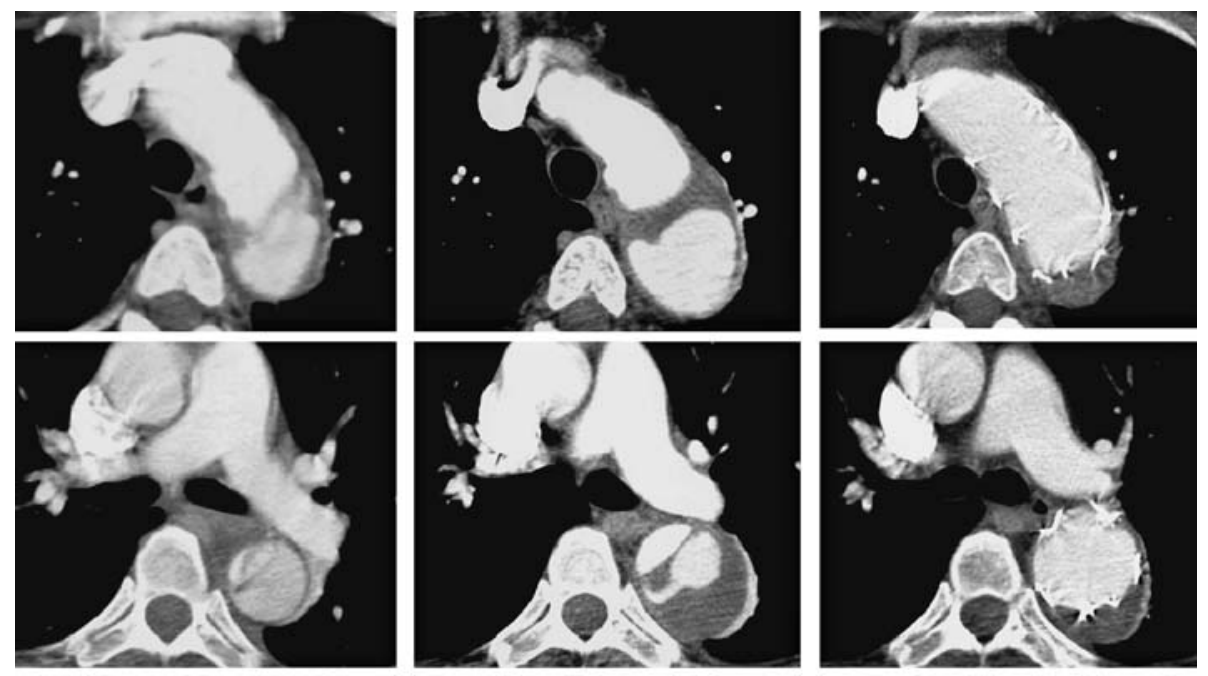

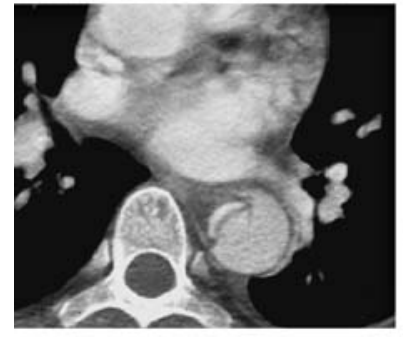

A

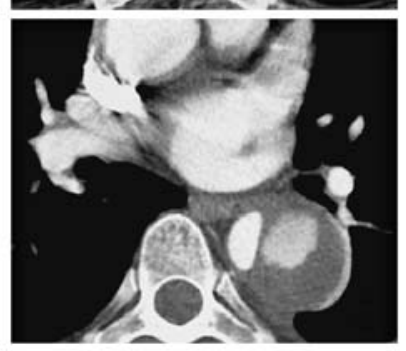

B

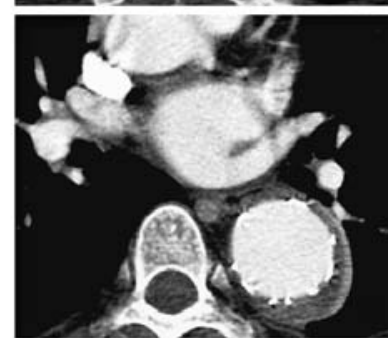

C

FIGURE 5. Serial CT imaging study demonstrating rapid false lumen enlargement within 3 months after the index hospitalization for acute type B dissection (A and B). Stent graft placement within chronic stage of disease enabled complete restoration of compressed true lumen and abolition of false lumen flow (C).

surgical repair whereas the majority of reinterventions were successfully managed endovascularly. Considering both open and auxiliary endovascular maneuvers, estimated freedom from reintervention was $71.5 \%$ at 36 months after initial stent graft implantation. Nevertheless, late aortic rupture and the need for secondary endovascular or surgical interventions may also be related to the progressive nature of the disease and may not necessarily reflect treatment failure. This is supported by the fact that $11 \%$ to $20 \%$ and $10 \%$ to $44 \%$ of patients with type B dissection require repeat surgery when treated medically or surgically, respectively. Notably, among all variables, Marfan syndrome was the only independent predictor of late surgical conversion in this series comprising 15 Marfan patients. Because of the inherent fragility of the aortic wall, endovascular treatment in patients with Marfan syndrome remains controversial. ${ }^{28,29}$ From a technical point of view, stent graft deployment was safe even in patients with Marfan syndrome and peri-interventional outcomes were satisfactory. Conversion to surgery in 6 patients and late aortic rupture in 3 patients, however, underscore that stent grafting should be considered a bridging maneuver to avoid (emergency) repeat surgery rather than a curative procedure. Furthermore, with the appearance of secondary endoleaks in about $50 \%$ of patients, both close surveillance and repeated imaging of the aorta appear man- datory to detect silent postinterventional complications eventually requiring additional maneuvers.

Experience with previously operated type A dissection and endovascular treatment in the chronic stage is rare. Our registry encompasses 9 patients with type A dissection treated endovascularly for residual distal false lumen flow. Although the favorable in-hospital survival and the low incidence of neurologic complications appear to be somewhat encouraging, it should be noted that $66.6 \%$ of patients encountered major adverse events, including redo procedures in 6 patients and fatal aortic rupture in 2 patients.

The present review has some limitations; owing to the retrospective nature, there was no control over the inclusion criteria for any endovascular procedure. The absence of a randomized or concurrent control group precluded direct comparison with conventional open repair or exclusive medical therapy. In addition, if we are to make any significant conclusions regarding the durability of endovascular therapy, it will be necessary to obtain longer term follow-up information. The currently available data on follow-up outcomes fail to provide precise morphologic information and rather focus on clinical end points. Therefore, distinct morphoanatomic long-term surveillance is important to asses any causal relationship between morphology and outcomes. Further investigation is crucial to understand the 
prognostic potential of acute and delayed stent graft placement in patients with thoracic aortic dissection.

In conclusion, endovascular treatment for thoracic aortic dissection with the Talent stent graft carried out at high-volume referral centers is associated with low early morbidity and mortality rates also for patients at high risk and treated on an emergency basis. Follow-up data indicate a satisfactory midterm durability of the procedure with an estimated $95.0 \%$ freedom from related death and an estimated $75.5 \%$ freedom from secondary interventions at 2 years. Although preliminary data suggest that stent graft repair may ultimately become the treatment of choice for most patients with distal dissections, the available evidence to date does not justify indiscriminate use of this technology in patients currently managed with medical therapy alone. Long-term surveillance will be crucial to discover complications unique to thoracic endovascular interventions and to determine which patients are appropriate candidates for stent graft therapy. Most important, comparative clinical trials are clearly needed to clarify the role of stent graft repair in the setting of both acute and chronic distal dissection.

\section{References}

1. Umana JP, Miller DC, Mitchell RS. What is the best treatment for patients with acute type B aortic dissections-medical, surgical, or endovascular stent-grafting? Ann Thorac Surg. 2002;74:S1840-3; discussion S1857-63.

2. Fattori R, Nienaber CA, Rousseau H, Beregi JP, Heijmen R, Grabenwöger M, et al. Results of endovascular repair of the thoracic aorta with the Talent Thoracic stent graft: the Talent Thoracic Retrospective Registry. J Thorac Cardiovasc Surg. 2006;132:332-9.

3. Leurs LJ, Bell R, Degrieck Y, Hobo R, Lundbom J; EUROSTAR; UK Thoracic Endograft Registry collaborators. Endovascular treatment of thoracic aortic diseases: combined experience from the EUROSTAR and United Kingdom Thoracic Endograft registries. J Vasc Surg. 2004;40:670-9; discussion 679-80.

4. Hagan PG, Nienaber CA, Isselbacher EM, Bruckman D, Karavite DJ, Russman PL, et al. The International Registry of Acute Aortic Dissection (IRAD): new insights into an old disease. JAMA. 2000;283:897-903.

5. Erbel R, Alfonso F, Boileau C, Dirsch O, Eber B, Haverich A, et al. Diagnosis and management of aortic dissection. Eur Heart J. 2001;22:1642-81.

6. Nienaber CA, Eagle KA. Aortic dissection: new frontiers in diagnosis and management. Part II: therapeutic management and follow-up. Circulation. 2003;108: $772-8$.

7. Brandt M, Hussel K, Walluscheck KP, Böning A, Rahimi A, Cremer J. Early and long-term results of replacement of the descending aorta. Eur J Vasc Endovasc Surg. 2005;30:365-9

8. Tsai TT, Fattori R, Trimarchi S, Isselbacher E, Myrmel T, Evangelista A, et al. Long-term survival in patients presenting with type B acute aortic dissection: insights from the International Registry of Acute Aortic Dissection. Circulation. 2006; 114:2226-31.

9. Estrera AL, Miller CC 3rd, Safi HJ, Goodrick JS, Keyhani A, Porat EE, et al. Outcomes of medical management of acute type B aortic dissection. Circulation. 2006;114(1 Suppl):I384-9.

10. Bernard Y, Zimmermann H, Chocron S, Litzler JF, Kastler B, Etievent JP, et al. False lumen patency as a predictor of late outcome in aortic dissection. Am J Cardiol. 2001;87:1378-82.

11. Juvonen T, Ergin MA, Galla JD, Lansman SL, McCullough JN, Nguyen K, et al. Risk factors for rupture of chronic type B dissections. J Thorac Cardiovasc Surg. 1999; 117:776-86.

12. Nienaber CA, Fattori R, Lund G, Dieckmann C, Wolf W, von Kodolitsch Y, et al. Nonsurgical reconstruction of thoracic aortic dissection by stent-graft placement. N Engl J Med. 1999;340:1539-45.

13. Dake MD, Kato N, Mitchell RS, Semba CP, Razavi MK, Shimono T, et al. Endovascular stent-graft placement for the treatment of acute aortic dissection. $N$ Engl J Med. 1999;340:1546-52.
14. Duebener LF, Lorenzen P, Richardt G, et al. Emergency endovascular stent-grafting for life-threatening acute type B aortic dissections. Ann Thorac Surg. Oct 2004;78(4):1261-6; discussion 1266-17.

15. Nathanson DR, Rodriguez-Lopez JA, Ramaiah VG, Misfeld M, Nötzold A Hartmann F, et al. Endoluminal stent-graft stabilization for thoracic aortic dissection. J Endovasc Ther. 2005;12:354-9.

16. Scheinert D, Krankenberg H, Schmidt A, Gummert JF, Nitzsche S, Scheinert S, et al. Endoluminal stent-graft placement for acute rupture of the descending thoracic aorta. Eur Heart J. 2004;25:694-700.

17. Nienaber CA, Zannetti S, Barbieri B, Kische S, Schareck W, Rehders TC. INSTEAD study collaborators. INvestigation of STEnt grafts in patients with type B Aortic Dissection: design of the INSTEAD trial-a prospective, multicenter European randomized trial. Am Heart J. 2005;149:592-9.

18. Greenberg R. Treatment of aortic dissections with endovascular stent grafts. Semin Vasc Surg. 2002;15:122-7.

19. Nienaber CA, Kische S, Zeller T, Rehders TC, Schneider H, Lorenzen B, et al Provisional extension to induce complete attachment after stent-graft placemen in type B aortic dissection: the PETTICOAT concept. J Endovasc Ther. 2006; 13:738-46.

20. Eggebrecht $H$, Nienaber CA, Neuhauser $M$, Baumgart $D$, Kische $S$, Schmermund A, et al. Endovascular stent-graft placement in aortic dissection: a meta-analysis. Eur Heart J. 2006;27:489-98.

21. Nienaber CA, Kische S, Ince H. Thoracic aortic stent-graft devices: problems, failure modes, and applicability. Semin Vasc Surg. 2007;20:81-9.

22. Shimono T, Kato N, Yasuda F, Suzuki T, Yuasa U, Onoda K, et al. Transluminal stent-graft placements for the treatments of acute onset and chronic aortic dissections. Circulation. 2002;106(12 Suppl. 1):I241-7.

23. Eggebrecht H, Herold U, Kuhnt O, Schmermund A, Bartel T, Martini S, et al. Endovascular stent-graft treatment of aortic dissection: determinants of post-interventional outcome. Eur Heart J. 2005;26:489-97.

24. Fattori R, Napoli G, Lovato L, Grazia C, Piva T, Rocchi G, et al. Descending thoracic aortic diseases: stent-graft repair. Radiology. 2003;229:176-83.

25. Wheatley GH 3rd, Gurbuz AT, Rodriguez-Lopez JA, Ramaiah VG, Olsen D, Williams J, et al. Midterm outcome in 158 consecutive Gore TAG thoracic endoprostheses: single center experience. Ann Thorac Surg. 2006;81:1570-7; discussion 1577 .

26. Rehders TC, Petzsch M, Ince H, Kische S, Korber T, Koschyk DH, et al. Intentional occlusion of the left subclavian artery during stent-graft implantation in the thoracic aorta: risk and relevance. J Endovasc Ther. 2004;11:659-66.

27. Fattori R, Lovato L, Buttazzi K, Di Bartolomeo R, Gavelli G. Extension of dissection in stent-graft treatment of type B aortic dissection: lessons learned from endovascular experience. J Endovasc Ther. 2005;12(3):306-11.

28. Ince H, Rehders TC, Petzsch M, et al. Stent-grafts in patients with marfan syndrome. J Endovasc Ther. Feb 2005;12:82-8.

29. Gaxotte V, Thony F, Rousseau H, Lions C, Otal P, Willoteaux S, et al. Midterm results of aortic diameter outcomes after thoracic stent-graft implantation for aortic dissection: a multicenter study. J Endovasc Ther. 2006;13:127-38.

\section{Discussion}

Dr R. Scott Mitchell (Stanford, Calif). I congratulate you on a truly fine presentation. It is a difficult subject. You and your coauthors report on a subject of great interest, that is, the long-term utility of endografts in both acute and chronic dissections. Although stent grafts may be truly lifesaving for patients with acute dissections who have malperfusion or impending rupture, many of us harbor significant reservations regarding their utility in uncomplicated type B dissections or in any chronic dissection. In this respect, $20 \%$ of your patients were treated urgently for acute complications, whereas the remainder were treated in a stable condition. In-hospital mortality occurred in 5\% of patients, 2 of whom died intraoperatively from ruptures of their dissection, which always is a very challenging patient cohort. Not surprisingly, older age, emergency status, and increasing ASA scores were independent predictors. Four patients had retrograde type A dissections in the acute phase, and 2 other patients had late type A dissections. This brings me to my first question. Do you have any information 
about these patients? Was it difficult to achieve a proximal seal? Did they get ballooning at the proximal anastomosis or proximal extensions? Can you elucidate on that?

Dr Ehrlich. Four of 7 patients had retrograde type A dissection within 30 days, and there is no doubt that this complication was associated with the stent-graft implantation. The only predictor that turned out to be statistically significant was the use of more stents, speculating that most of those patients did not have a sealing of the primary tear in the first place. An additional stent was positioned in the proximal arch with balloon dilatation, and as a consequence of the procedure an intimal tear with retrograde dissection developed.

With regard to the 3 patients who had retrograde type A dissection after discharge, we can only speculate that it might have been some complication of the stent-graft treatment. All of those patients were operated on, and a new type A dissection developed in some of them, but we do not have any information on those 3 patients.

Dr Mitchell. Overall, as you noted, early results were good, but the late results are of more interest. Here, unfortunately, information is more limited. Although survival at 36 months was $81 \%$, this is a limited measure of success inasmuch as $80 \%$ of these patients were really treated in the uncomplicated and asymptomatic state. More important would be what happened to the aortas in these chronic dissections? You tell us that despite a $20 \%$ incidence of primary type I endoleaks, an increase in aortic size occurred in only $20 \%$ of patients, and $55 \%$ and $25 \%$, respectively, showed no change in size or a decrease. However, and herein lies my problem with this paper, only $60 \%$ of patients had any imaging past 12 months. Although survival and freedom from reintervention rates are good, we really do not know what happened to the aortas in these patients in the late stage. Thus, I have three other questions.

I noted that 15 patients with the Marfan syndrome were treated and that Marfan actually in the univariate analysis was a predictor of in-hospital death. Do you still recommend stent-graft treatment for primary dissections in patients with Marfan syndrome?

Dr Ehrlich. Thank you, Dr. Mitchell, for this excellent comment. Fifteen patients with Marfan syndrome were included in the study. Two of them had acute complicated type B dissection, in which I see the only indication for stent-graft placement probably as a bridging procedure to late elective surgery. The other 13 patients had chronic type B dissection. In my personal opinion, I would not recommend stent grafting for these patients, as they are usually relatively young and I think they would have a relatively low morbidity or mortality if they where to be operated on conventionally.

Dr Mitchell. We concur with that entirely.

With regard to spinal cord injury, did this appear in the acute phase or were these delayed paraplegias? Do we have any infor- mation as to the distal extent of your stent grafts? We are particularly paranoid about allowing our stent grafts below the T6 or T7 level.

Dr Ehrlich. Spinal cord injury developed in 4 patients, and the injury occurred right after stent-graft placement. There were no instances of delayed onset of paraplegia. However, in 2 patients, the paraplegia resolved, resulting in a permanent paraplegia rate of $2 \%$. It must be stressed, however, that in none of these patients was the left subclavian artery overstented and in none of these patients were multiple stents used.

Dr Mitchell. In cases of chronic dissection, do you have any information on the behavior of the false lumen or thrombosis thereof during late follow-up?

I applaud your attempt to provide critical information on this difficult patient cohort.

Dr Ehrlich. The false lumen was thrombosed in 59\% of all patients. It was partially thrombosed in $20 \%$, and no thrombosis occurred in $20 \%$. However, we saw a trend that in acute type B dissection the rate of false lumen thrombosis was higher.

Dr Thomas M. Beaver (Gainesville, Fla). I am curious about the $29 \%$ incidence of endoleaks, or primary type I endoleaks, and the reasons for reintervention. Traditionally, type B dissections are treated medically and if the aorta is not aneurysmal, we would not be intervening. What were the reasons for intervention on the type I endoleaks?

Dr Ehrlich. The major finding in this study is that acute complicated type $\mathrm{B}$ dissection can be nicely treated with a stent device; however, in chronic type B dissection the results were very bleak and actually comparable to medical treatment. I think our data are confirmed by the INSTEAD* trial, or, let's say differently, the INSTEAD trial confirms our observation that probably patients with chronic type B dissections are better off with medical treatment.

Dr D. Craig Miller (Stanford, Calif). I also have reviewed this paper. The results in the patients with complicated acute type B dissections, people dying right under your nose, are superb. You do have some 1- to 2-year data that show this is really where this technology is going to save lives. Conversely, you have not persuaded me that stent grafting offers any favorable effects or protection for patients with chronic uncomplicated dissections. Just because stent grafting can be done with low morbidity and mortality risk does not mean it should be done.

Dr Ehrlich. I fully agree with you.

Dr Miller. Your coauthors may not, though. This is difficult for Marek as he is representing a very diverse group of interventional radiologists and cardiologists and cardiac surgeons from many different centers. 